
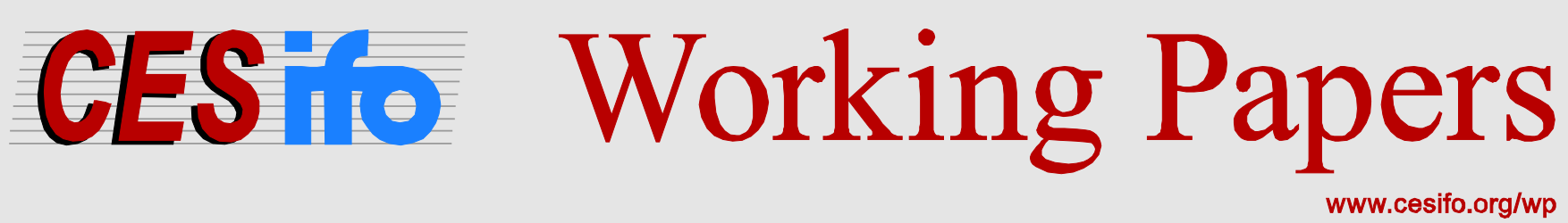

\title{
Abatement Innovation in a Cournot Oligopoly: Emission versus Output Tax Incentives
}

\author{
Naoto Aoyama \\ Emilson C. D. Silva
}

\author{
CESIFO WORKING PAPER NO. 6094 \\ CATEGORY 10: ENERGY AND CLIMATE ECONOMICS \\ SEPTEMBER 2016
}

An electronic version of the paper may be downloaded

- from the SSRN website:

- from the RePEc website:

- from the CESifo website:

www.SSRN.com

Www.RePEc.org

www.CESifo-group.org/wp 


\title{
Abatement Innovation in a Cournot Oligopoly: Emission versus Output Tax Incentives
}

\begin{abstract}
This study compares energy and emission taxes used to control pollution and provide incentives for the adoption of an advanced abatement technology in a Cournot oligopoly. We examine multistage games where the government may intervene in order to maximize social welfare by setting an environmental tax rate. When the government intervenes, it levies either an energy tax or an emission tax. We show that the effectiveness of either type of tax depends on the shape of the multiproduct technology. In the absence of economies of scope in the production of energy and abatement, the energy tax reduces pollution but is ineffective in promoting technological change. The emission tax reduces pollution and is effective in promoting technological change for sufficiently small fixed costs of adoption. In the presence of economies of scope, firms may adopt the efficient technology even in the absence of taxation. When taxation is necessary for innovation, both types of taxes are effective. However, the energy tax outperforms the emission tax in terms of innovation incentives.
\end{abstract}

JEL-Codes: D210, D620, D780, L130, H230, O330.

Keywords: externalities, output taxes, emission taxes, technology adoption, Cournot duopoly.

Naoto Aoyama

Aomori Public University

153-4 Yamazaki, Goshizawa

Japan - Aomori 030-0196

aoyama@bb.nebuta.ac.jp
Emilson C. D. Silva

University of Alberta

Edmonton / Alberta / Canada

emilson@ualberta.ca

September 12, 2016 


\section{Introduction}

According to the Organisation for Economic Co-operation and Development (OECD, 2005), “An environmental tax is a tax whose tax base is a physical unit (or a proxy of it) that has a proven specific negative impact on the environment. Four subsets of environmental taxes are distinguished: energy taxes, transport taxes, pollution taxes and resources taxes. Taxes should be confounded neither with payments of rent nor with purchase of an environmental protection service.” In another report, OECD (2010), we learn that environmental innovations can take various forms: (i) use less-emission-intensive inputs of the same type, (ii) use less-emissionintensive inputs of different types, (iii) reduce pollution intensity per unit of input without modifying inputs, (iv) reduce input use per unit of output, and (v) end-of-pipe technology. If an environmental tax is levied on pollution, firms may have incentives to promote all these types of innovation. An indirect tax on pollution, however, is more limiting: it can only provide incentives for innovations of types (i), (iii), and (iv).

In this paper, we study the effectiveness of environmental taxation in promoting the adoption of an advanced abatement technology. We study two types of taxes, one that taxes emissions (i.e., a direct tax on pollution) and another that taxes output (i.e., an indirect tax on pollution). One of the important messages of this paper is that the effectiveness of the direct tax relative to the indirect tax depends on the shape of the multiproduct technology. Firms may produce two outputs, the final consumption good, whose production causes pollution, and abatement product, which reduces pollution. The direct tax is more effective if the multiproduct technology features diseconomies of scope. However, the indirect tax is more effective if the multiproduct technology features economies of scope provided the degree of complementarity between the two products is sufficiently large. 
According to Cremer and Gahvari (2002):

"In most textbook models of externality the question of the choice between emission and output taxes does not arise: they are equivalent. Yet this is an important policy question. The equivalence of the tax instruments in these models is an artifact of an assumed one-to-one relationship between emissions and polluting good. This is an unrealistic assumption. Input substitution, employing different technologies and abatement imply that a given level of output may result in different levels of emissions. Allowing for these possibilities breaks up the equivalence of output and emission taxes and allows one to study the role of these and other tax instruments in implementing different public policy objectives." (Cremer and Gahvari, 2002, pp. 385-386).

Schmutzler and Goulder (1997) and by Cremer and Gahvari (2001) review the related literature and show that typically the papers in this literature assume that a direct tax is a tax on emissions of certain pollutants and that an indirect tax is a tax on the output of a firm for which production entails emissions of certain pollutants. Katsoulacos and Xepapadeas (1996) examines optimal emission taxes under perfect competition, monopoly and oligopoly. They show that the optimal emission tax depend on the marginal pollution damage and on the distortion produced by market power.

In our model, the firms are oligopolistic. The industry is composed of $n \geq 2$ firms. Each firm produces an amount of a homogeneous consumption good, which we call 'energy'. Energy production leads to the emission of a pollutant (say, carbon dioxide). Each firm may reduce its emission level by producing abatement. If the firm produces abatement, it can also exert effort in the production of green R\&D in order to reduce the cost of producing abatement. Each firm has two types of abatement technology available. One, which we call 'standard', can be utilized 
without incurring any fixed cost. The other, which requires a fixed cost of adoption, we call 'advanced'. The advanced technology is more efficient than the standard technology since the total and marginal costs of producing abatement under the advanced technology are lower than under the standard technology. The standard and advanced technologies are multiproduct technologies. The multiproduct technologies may feature diseconomies of scope (absence of cost complementarity) or economies of scope (presence of cost complementarity).

There is a government in the economy with the mandate to set environmental policy in order to control pollution. Environmental policy takes one of two forms, an energy tax or a tax on emissions. In the status quo, the government does not intervene. In this setting, the firms play a two stage game. In the first stage, each firm decides whether to innovate, taking the actions of all other firms as given. Prior to the beginning of the second stage, each firm observes the technological choices made by all other firms. In the second stage, each firm chooses R\&D effort and energy and abatement output levels, taking all other firms' choices as given. The subgame perfect Nash equilibrium for this game provides us with the benchmark for future comparisons. When the government intervenes, either by setting an energy tax rate or by setting an emission tax rate, the game played by the government and firms have three stages. In the first stage, the government sets the tax rate. In the second and third stages, the firms make choices as in the benchmark game. We later compare all subgame perfect equilibria in order to find the circumstances under which environmental policy is effective in promoting incentives for innovation.

Few studies have compared an emission tax with an output tax. Schmutzler and Goulder (1997) examine an emission tax and an output tax to improve environmental quality under uncertain circumstances. In a perfect monitoring case, the regulator can achieve the first-best 
allocation using a pure emission tax. With imperfect monitoring, pure emission taxes are not optimal with monitoring costs. Starting from this point, they characterize the optimal conditions for an output tax. With sufficiently high monitoring costs, sufficiently limited options of emission reduction other than output reduction, and sufficiently high substitutability of the output, the output tax is more desirable than the emission tax.

Cremer and Gahvari (2001) examine the optimality for output taxes, emission taxes, and mixed taxes. Under full information, the first-best Pigouvian rule requires that the marginal private benefit of emissions in production be equal to the marginal social damage by emissions. Under limited information, the modified Pigouvian rule requires that the marginal emission tax be equal to the marginal social damage of emissions plus an adjustment term. The term reflects the impact of marginal emissions on the incentive compatibility constraint.

Many studies examine how environmental policies may promote the adoption of advanced technology for the control of pollution emissions (e.g., Downing and White (1986), Milliman and Prince (1989), Jung et al. (1996), Jaffe et al. (2002), Fowlie (2010), Acemoglu et al. (2012)). Typically, the theoretical papers consider situations in which all firms adopt the new technology. Requate and Unold (2003) extend the studies of Milliman and Prince (1989) and Jung et al. (1996). They consider a case in which the number of firms that adopt an advanced technology is determined endogenously through equilibrium considerations. They assess how many firms will invest in and adopt a new technology in equilibrium under taxes, subsidies, auctioned permits, grandfathering permits, and command and control. If the regulator does not anticipate the new technology, then taxes and subsidies on abatement provide higher incentives among policy instruments. If the regulator does anticipate the new technology, then when firms move first and the regulator moves second, taxes and all permit regimes are superior to standards; alternatively, 
when the regulator moves first and firms move second, only permits succeed in achieving the firstbest allocation. In a recent, empirical paper, Fowlie (2010) shows that environmental regulations have been crucial motivators for the adoption of advanced, cleaner, technologies in the electricity sector in the United States. Acemoglu et al. (2012) consider a growth model with environmental constraints and endogenous and directed technical change. They show that the optimal intertemporal policy must use a tax on dirty input production to control carbon emissions and a subsidy on clean R\&D in order to influence the type of research activity.

Schmutzler and Goulder (1997) and Cremer and Gahvari (2001) devote attention to the choice problem between emission and output taxes, but they do not consider the impact of these taxes on promotion of an advanced abatement technology. Milliman and Prince (1989), Jung et al. (1996), and Requate and Unold (2003) consider rankings among emission taxes, subsidies, permits and command and control to promote an advanced abatement technology, but they do not consider the effects of energy taxes. Unlike these papers, we consider the effectiveness of energy and emission taxes in the adoption of an advanced abatement technology. We also consider multiproduct technologies that feature economies or diseconomies of scope. We show that the shape of the multiproduct technology is crucial in determining which type of tax is more effective in promoting adoption of an advanced abatement technology in a Cournot oligopoly.

We organize the paper as follows. Section 2 presents the basic model. We derive the optimal values for the benchmark game, without taxation. In section 3, we examine the three-stage game in which the government chooses the energy tax rate. In section 4, we consider the threestage game in which the government chooses the emission tax rate. Section 5 combines the results and discusses the circumstances under which each type of tax is more effective in promoting innovation. Section 6 concludes the paper. 


\section{Basic Model}

Consider an economy with two private goods. One good is the numeraire and the other good is a final consumption good, which is produced by an oligopoly. For simplicity, we normalize the number of consumers to be equal to one. Assume that this "market” consumer utility is as follows: $u=x+y(1-y / 2)-E^{2} / 2$, where $x$ denotes the consumption level of the numeraire good, $y$ is the consumption level of the good (henceforth, called 'energy'), which is produced by the oligopoly and whose production generates pollution and $E$ is the total amount of emissions generated by the energy sector (say, the level of air pollution). The consumer's budget constraint is $x+p y=w$, where $w=x^{o}+\sum_{i=1}^{n} \pi_{i}$ and $\pi_{i}$ is the profit earned by firm $i$. There are $n \geq 2$ firms in the industry.

The consumer chooses non-negative $y$ to maximize $w-p y+y(1-y / 2)-E^{2} / 2$, taking $p$ and $E$ as given. Assuming an interior solution, the first order condition yields $y=1-p$, the market demand for energy. It follows that the consumer's indirect utility is $v=w+\left[(1-p)^{2}-E^{2}\right] / 2$. Let $Q=\sum_{i=1}^{n} q_{i}$ denote the market supply of the polluting good, where $q_{i}$ is firm $i$ 's energy output. The market clearing condition, $y=Q$, yields $p(Q)=1-Q$.

In addition to producing energy, each firm may also produce pollution abatement, exert effort in cost-reducing green R\&D and emit pollution (e.g., carbon dioxide). Let $a_{i} \geq 0$ and $r_{i} \geq 0$ denote the amounts of abatement and green $R \& D$ provided by firm $i$. In the production process, 
firm $i$ emits $e_{i}=q_{i}-a_{i}$ units of carbon dioxide. The industry's emission is $E=\sum_{i=1}^{n} e_{i}=Q-A$, where $A=\sum_{i=1}^{n} a_{i}$.

Hence, we assume that firm $i$ utilizes a multiproduct technology and has the following profit function:

$$
\pi_{i}=p(Q) q_{i}-\frac{q_{i}^{2}}{2}-\theta_{i} \gamma_{i}\left(a_{i}-r_{i}\right)^{2}-\chi a_{i} q_{i}-\frac{r_{i}^{2}}{2}-\sigma_{i} f
$$

where the first three components of the cost function represent the joint cost of producing energy and pollution abatement. We assume that $\theta_{i}=1$ if firm $i$ utilizes a standard technology, $\theta_{i}=1 / 2$ if firm $i$ adopts an advanced technology, $\gamma_{i}=0$ if $a_{i}=0, \gamma_{i}=1$ if $a_{i}>0$, and $\chi \in[-1 / 2,1 / 2]$ is a technology parameter which informs us if the standard or advanced technology features economies of scope $(\chi<0)$, diseconomies of scope $(\chi>0)$, or is separable in energy and pollution abatement outputs $(\chi=0)$. If firm $i$ does not provide abatement, its profit function decreases with $R \& D$ effort because the cost of $R \& D$ effort is $r_{i}^{2} / 2$. Hence, in such a case it is not rational for firm $i$ to exert effort in $\mathrm{R} \& \mathrm{D}$, implying that $r_{i}=0$. If $a_{i}>0$, on the other hand, it may be optimal for firm $i$ to exert effort in R\&D. Finally, the last term in (1) is the fixed cost faced by firm $i$ with the adoption of the advanced technology, where that $\sigma_{i}=0$ if firm $i$ utilizes the standard technology and $\sigma_{i}=1$ if firm $i$ adopts the advanced technology. Assume that $f>0$.

The firms play a two-stage game. In the first stage, each firm decides which type of technology it will utilize, taking the choices of all other firms as given. After these choices take place, each firm observes the technologies utilized by all firms in the industry and then in the 
second stage chooses energy, abatement and R\&D levels, taking the choices of all other firms as given. The equilibrium concept is subgame perfection.

\subsection{In the Absence of Economies of Scope}

Suppose initially that $\chi \geq 0$. The following result is immediate.

Proposition 1. If $\chi \geq 0$, then, for $i=1, \ldots, n$, the subgame perfect equilibrium is characterized by

i. $\quad a_{i}=\gamma_{i}=r_{i}=\sigma_{i}=0$,

ii. $\quad q_{i}=\frac{1}{n+2}$,

iii. $\quad p=\frac{2}{n+2}$,

iv. $\quad \pi_{i}=\frac{3}{2(n+2)^{2}}$,

v. $E=Q=\frac{n}{n+2}$.

Proof. Let $\chi \geq 0$. Consider (1). Note that (1) decreases in $a_{i}$. This implies that $a_{i}=0$. Hence, $\gamma_{i}=0$ and subsequently $r_{i}=0$. Firm $i$ chooses $q_{i} \geq 0$ to maximize $p(Q) q_{i}-q_{i}^{2} / 2$, where $Q=q_{i}+\sum_{h \neq i}^{n} q_{h}$, taking the other firms' energy output choices as given. The first order conditions, which are necessary and sufficient, yield $q_{i}=p / 2, \forall i$. Thus, $Q=n p / 2$. Plugging this into $p(Q)=1-Q$ and solving it, we obtain $p=2 /(n+2)$. Therefore, $Q=n q_{i}=n /(n+2)$. Since $a_{i}=0, \forall i, e_{i}=q_{i}$ and $E=Q$. Firm $i$ 's profit in the second stage is $\pi_{i}=\frac{3}{2(n+2)^{2}}-\sigma_{i} f$.

Knowing this, firm $i$ chooses $\sigma_{i}=0$ in the first stage. Q.E.D. 
No firm has an incentive to produce abatement, exert effort in R\&D and adopt the advanced technology. As a result, the total emission level produced by industry is equal to the industry's energy output. Given this, the welfare level in the economy is

$$
u=w=x^{o}+\sum_{i=1}^{n} \pi_{i}=x^{o}+\frac{3 n}{2(n+2)^{2}} .
$$

\subsection{In the Presence of Economies of Scope}

Suppose now that $\chi<0$. Assume that $a_{i}>0$. Then, $\gamma_{i}=1$. Given this and assuming that the choices of energy and R\&D effort yield strictly positive amounts, firm i 's first order conditions are as follows:

$$
\begin{aligned}
& -2 \theta_{i}\left(a_{i}-r_{i}\right)-\chi q_{i}=0, \\
& p-2 q_{i}-\chi a_{i}=0, \\
& 2 \theta_{i}\left(a_{i}-r_{i}\right)-r_{i}=0 .
\end{aligned}
$$

Solving the system of equations (3) - (5) yields

$$
\begin{gathered}
a_{i}=-\frac{\chi p\left(1+2 \theta_{i}\right)}{4 \theta_{i}-\left(1+2 \theta_{i}\right) \chi^{2}}, \\
q_{i}=\frac{2 \theta_{i} p}{4 \theta_{i}-\left(1+2 \theta_{i}\right) \chi^{2}}, \\
r_{i}=-\frac{2 \chi \theta_{i} p}{4 \theta_{i}-\left(1+2 \theta_{i}\right) \chi^{2}} .
\end{gathered}
$$

It can be easily checked that for $\theta_{i} \in\{1 / 2,1\}$ and $\chi \in[-1 / 2,1 / 2]$, the common denominator in (6)

- (8) is greater than zero. Since $Q=\sum_{j=1}^{n} q_{j}$ and $p(Q)=1-Q$, we obtain 


$$
\begin{aligned}
& p=\frac{1}{1+2 \sum_{j=1}^{n}\left[\frac{\theta_{j}}{4 \theta_{j}-\left(1+2 \theta_{j}\right) \chi^{2}}\right]}, \\
& Q=\frac{2 \sum_{j=1}^{n}\left[\frac{\theta_{j}}{4 \theta_{j}-\left(1+2 \theta_{j}\right) \chi^{2}}\right]}{1+2 \sum_{j=1}^{n}\left[\frac{\theta_{j}}{4 \theta_{j}-\left(1+2 \theta_{j}\right) \chi^{2}}\right]} .
\end{aligned}
$$

Let $\alpha_{j} \equiv \theta_{j} /\left[4 \theta_{j}-\left(1+2 \theta_{j}\right) \chi^{2}\right]$. Then, combining (7) and (9) we can write

$$
q_{i}\left(\theta_{i} ; \boldsymbol{\theta}_{-i}\right)=\frac{2 \alpha_{i}\left(\theta_{i}\right)}{1+2 \alpha_{i}\left(\theta_{i}\right)+2 \sum_{h \neq i}^{n} \alpha_{h}\left(\theta_{h}\right)} .
$$

Equation (11) clearly demonstrates that firm i's output depends on the technologies choices made by all firms in the industry. The following result shows that firm $i$ produces more output when it innovates, taking all other firms’ choices as given.

Proposition 2. $q_{i}\left(1 / 2 ; \boldsymbol{\theta}_{-i}\right)>q_{i}\left(1 ; \boldsymbol{\theta}_{-i}\right)$.

Proof. $q_{i}\left(1 / 2 ; \boldsymbol{\theta}_{-i}\right)>q_{i}\left(1 ; \boldsymbol{\theta}_{-i}\right)$ if and only if

$$
\frac{1}{2\left(1-\chi^{2}\right)}\left[\frac{1}{1+\frac{2}{4\left(1-\chi^{2}\right)}+2 \sum_{h \neq i}^{n} \alpha_{h}\left(\theta_{h}\right)}\right]>\frac{2}{\left(4-3 \chi^{2}\right)}\left[\frac{1}{1+\frac{2}{4-3 \chi^{2}}+2 \sum_{h \neq i}^{n} \alpha_{h}\left(\theta_{h}\right)}\right],
$$

which is true because

$$
4-3 \chi^{2}+2+2\left(4-3 \chi^{2}\right) \sum_{h \neq i}^{n} \alpha_{h}\left(\theta_{h}\right)>4\left(1-\chi^{2}\right)+2+8\left(1-\chi^{2}\right) \sum_{h \neq i}^{n} \alpha_{h}\left(\theta_{h}\right) .
$$

Q.E.D.

Given (6) - (11), we can write firm $i$ 's profit in the second stage as follows: 


$$
\pi_{i}\left(\theta_{i}, \sigma_{i}, \chi, f ; \boldsymbol{\theta}_{-i}\right)=\left[3-\frac{\left(1+2 \theta_{i}\right) \chi^{2}}{2 \theta_{i}}\right] \frac{q_{i}^{2}\left(\theta_{i} ; \boldsymbol{\theta}_{-i}\right)}{2}-\sigma_{i} f
$$

Consider the first stage of the game. Taking all other firms' choices as given, firm $i$ finds it optimal to innovate if the fixed cost is sufficiently small:

Proposition 3. $\theta_{i}=1 / 2$ and $\sigma_{i}=1$ if and only if

$$
f \leq \frac{2\left(3-2 \chi^{2}\right) q_{i}^{2}\left(1 / 2 ; \boldsymbol{\theta}_{-i}\right)-3\left(2-\chi^{2}\right) q_{i}^{2}\left(1 ; \boldsymbol{\theta}_{-i}\right)}{4}
$$

Proof. From (12), $\pi_{i}\left(1 / 2,1, \chi, f ; \boldsymbol{\theta}_{-i}\right) \geq \pi_{i}\left(1,0, \chi ; \boldsymbol{\theta}_{-i}\right)$ if and only if (13) holds. Q.E.D.

In the presence of economies of scope, each firm adopts the advanced technology if (13) holds. The dependence of the adoption decision on taxation (either output or emission tax) holds only if (13) does not hold. For the future reference, let us denote $f=f^{1}$ the isoprofit curve where (13) holds with equality. ${ }^{1}$

Next, we derive the social welfare. If $\theta_{i}=1 / 2$ and $\sigma_{i}=1, \forall i=1, \ldots, n$, we obtain

$$
\begin{gathered}
q_{i}(1 / 2 ; \mathbf{1} / \mathbf{2}, \chi, n)=1 /\left[n+2\left(1-\chi^{2}\right)\right] \\
\text { and } \pi_{i}(1 / 2,1 ; \mathbf{1} / \mathbf{2}, \chi, n, f)=\left(3-2 \chi^{2}\right) / 2\left[n+2\left(1-\chi^{2}\right)\right]^{2}-f
\end{gathered}
$$

If $\theta_{i}=1$ and $\sigma_{i}=0, \forall i=1, \ldots, n$, we obtain

$$
q_{i}(1 ; 1, \chi, n)=2 /\left(2 n+4-3 \chi^{2}\right) \text { and } \pi_{i}(1,0 ; 1, \chi, n)=3\left(2-\chi^{2}\right) /\left(2 n+4-3 \chi^{2}\right)^{2}
$$

Then, the social welfare levels are

\footnotetext{
${ }^{1}$ We use superscript " 1 ” to denote no tax regime. We also use superscript " 2 ", “ 3 " and "0" to denote energy tax regime, emission tax regime and the socially desirable, respectively.
} 


$$
\left\{\begin{array}{c}
u(\mathbf{1} / \mathbf{2}, \mathbf{1}, \chi, n, f)=x^{o}+\frac{n\left[3-2 \chi^{2}-4 n \chi(1+\chi)\right]}{2\left[n+2\left(1-\chi^{2}\right)\right]^{2}}-n f \\
u(\mathbf{1}, \mathbf{0}, \chi, n)=x^{o}+\frac{3 n\left[2\left(2-\chi^{2}\right)-n \chi(4+3 \chi)\right]}{2\left(2 n+4-3 \chi^{2}\right)^{2}}
\end{array}\right.
$$

\section{Energy Tax}

In this section, we examine the government's optimal choices concerning the output tax. We shall henceforth refer to this tax as 'energy tax'. As usual, we assume that the government sets the tax prior to the choices made by firms. We consider a three-stage game. In the first stage, the government chooses an energy tax rate $t$. In the second stage, each frim observes the energy tax rate, and then chooses whether to innovate. In the third stage, each firm chooses energy, abatement and green R\&D levels after observing the choices made in the first and second stages.

Firm $i$ 's profit function is now

$$
\pi_{i}=p(Q) q_{i}-\frac{q_{i}^{2}}{2}-\theta_{i} \gamma_{i}\left(a_{i}-r_{i}\right)^{2}-\chi a_{i} q_{i}-\frac{r_{i}^{2}}{2}-\sigma_{i} f-t q_{i},
$$

The tax revenue is returned to the consumer in a lump-sum fashion. The welfare level in the economy is

$$
u=x^{o}+\sum_{i=1}^{n} \pi_{i}+t \sum_{i=1}^{n} q_{i}+\left[(1-p)^{2}-E^{2}\right] / 2 .
$$

\subsection{In the Absence of Economies of Scope}

As in the previous section, if $\chi \geq 0$, then $a_{i}=0, \gamma_{i}=0$ and $r_{i}=0$. Assume that $q_{i}>0$. Firm $i$ 's first order condition yields

$$
2 q_{i}=p-t
$$

Equation (17) implies that $q_{i}=Q / n, i=1, \ldots, n$. Since $p=1-Q$, we have 


$$
\begin{aligned}
& p=(n t+2) /(n+2), \\
& Q=n(1-t) /(n+2) .
\end{aligned}
$$

Then we can write

$$
q_{i}(t)=(1-t) /(n+2)
$$

Utilizing (20), we obtain $\pi_{i}=\frac{3(1-t)^{2}}{2(n+2)^{2}}-\sigma_{i} f$.

Consider the second stage. Given (20), we obtain $\theta_{i}=1$ and $\sigma_{i}=0$. The choice to maintain the standard technology is a dominant strategy for each firm. Hence, we have $\theta_{j}=1$ and $\sigma_{j}=0$, $j=1, \ldots, n$ in the second stage of the game.

Consider the first stage. The government knows that no firm will innovate. The government chooses $t \in[0,1]$ to maximize (16) subject to (18) - (20) and $E=Q$. The objective function reduces to $x^{o}+n(1-t)[2(n+2) t+3(1-t)] / 2(n+2)^{2}$. Assuming an interior solution, the first order condition yields

$$
t=\frac{n-1}{2 n+1}
$$

Note that the optimal tax rate is an increasing function of the number of firms in the industry.

The following proposition summarizes the results of this section.

Proposition 4. If $\chi \geq 0$, then, for $i=1, \ldots, n$, the subgame perfect equilibrium is characterized by

$$
\begin{aligned}
& \text { i. } a_{i}=\gamma_{i}=r_{i}=\sigma_{i}=0, \\
& \text { ii. } \quad t=\frac{n-1}{2 n+1}
\end{aligned}
$$


iii. $\quad q_{i}=\frac{1}{2 n+1}$,

iv. $\quad p=\frac{n+1}{2 n+1}$,

v. $\quad \pi_{i}=\frac{3}{2(2 n+1)^{2}}$,

vi. $\quad E=Q=\frac{n}{2 n+1}$.

Given the results above, the social welfare level is

$$
u=x^{o}+\frac{n}{2(2 n+1)}
$$

Even though the energy tax does not provide incentives to innovate, social welfare improves with the tax because it reduces the pollution level. By comparing (22) and (3), we see that welfare is higher under the energy tax relative to no tax for $n \geq 2$. Relative to no taxation, the amount of pollution is also lower with the energy tax for $n \geq 2$.

\subsection{In the Presence of Economies of Scope}

Suppose that $\chi<0$. Assume that $a_{i}>0$ and subsequently $\gamma_{i}=1$. Assume also that $q_{i}>0$ and $r_{i}>0$. Firm $i$ 's first order conditions yield

$$
\begin{aligned}
& 2 \theta_{i}\left(a_{i}-r_{i}\right)=-\chi q_{i}, \\
& 2 q_{i}=p-\chi a_{i}-t, \\
& 2 \theta_{i}\left(a_{i}-r_{i}\right)=r_{i} .
\end{aligned}
$$

Solving the system of equations (23) - (25) yields

$$
a_{i}=-\frac{\chi\left(1+2 \theta_{i}\right)(p-t)}{4 \theta_{i}-\left(1+2 \theta_{i}\right) \chi^{2}}
$$




$$
\begin{aligned}
q_{i} & =\frac{2 \theta_{i}(p-t)}{4 \theta_{i}-\left(1+2 \theta_{i}\right) \chi^{2}}, \\
r_{i} & =-\frac{2 \chi \theta_{i}(p-t)}{4 \theta_{i}-\left(1+2 \theta_{i}\right) \chi^{2}} .
\end{aligned}
$$

Since $Q=\sum_{j=1}^{n} q_{j}$ and $p=1-Q$, we have

$$
\begin{gathered}
p=\frac{1+2 t \sum_{j=1}^{n} \alpha_{j}}{1+2 \sum_{j=1}^{n} \alpha_{j}}, \\
Q=\frac{2(1-t) \sum_{j=1}^{n} \alpha_{j}}{1+2 \sum_{j=1}^{n} \alpha_{j}} .
\end{gathered}
$$

Combining (27) and (29), we can write

$$
q_{i}\left(\theta_{i} ; t, \boldsymbol{\theta}_{-i}\right)=\frac{2(1-t) \alpha_{i}\left(\theta_{i}\right)}{1+2 \alpha_{i}\left(\theta_{i}\right)+2 \sum_{h \neq i}^{n} \alpha_{h}\left(\theta_{h}\right)}
$$

As before, firm $i$ produces more output when it innovates:

Proposition 5. $q_{i}\left(1 / 2 ; t, \boldsymbol{\theta}_{-i}\right)>q_{i}\left(1 ; t, \boldsymbol{\theta}_{-i}\right)$.

Proof. From (31), $q_{i}\left(1 / 2 ; t, \boldsymbol{\theta}_{-i}\right)>q_{i}\left(1 ; t, \boldsymbol{\theta}_{-i}\right)$, which is true from (11) and proposition 2. Q.E.D.

Firm $i$ 's profit in the third stage is

$$
\pi_{i}\left(\theta_{i}, \sigma_{i}, \chi, f ; t, \boldsymbol{\theta}_{-i}\right)=\left[3-\frac{\left(1+2 \theta_{i}\right) \chi^{2}}{2 \theta_{i}}\right] \frac{q_{i}^{2}\left(\theta_{i} ; t, \boldsymbol{\theta}_{-i}\right)}{2}-\sigma_{i} f .
$$

Consider the second stage. Given (32), we obtain

Proposition 6. $\theta_{i}=1 / 2$ and $\sigma_{i}=1$ if and only if 


$$
f \leq \frac{2\left(3-2 \chi^{2}\right) q^{2}\left(1 / 2 ; t, \boldsymbol{\theta}_{-i}\right)-3\left(2-\chi^{2}\right) q^{2}\left(1 ; t, \boldsymbol{\theta}_{-i}\right)}{4}
$$

Proof. From (32), $\pi_{i}\left(1 / 2,1, \chi, f ; t, \boldsymbol{\theta}_{-i}\right) \geq \pi_{i}\left(1,0, \chi ; t, \boldsymbol{\theta}_{-i}\right)$ if and only if (33) holds. Q.E.D.

Let us denote $f=f^{2}$ the isoprofit curve where (33) holds with equality. If (33) holds, we have $\theta_{j}=1 / 2$ and $\sigma_{j}=1, j=1, \ldots, n$ in the second stage of the game. If not, we have $\theta_{j}=1$ and $\sigma_{j}=0, j=1, \ldots, n$. The government anticipates the choices made in the second and third stages and then chooses $t \in[0,1]$ to maximize (16) subject to (26) - (30) and $E=Q-\sum_{j=1}^{n} a_{j}$. If innovation is optimal, $\theta_{i}=1 / 2$ and $\sigma_{i}=1, \forall i=1, \ldots, n$. The government's objective function reduces to

$$
x^{o}-n f+\frac{n(1-t)}{n+2\left(1-\chi^{2}\right)}\left\{t+\frac{(1-t)\left[n-n(1+2 \chi)^{2}+\left(3-2 \chi^{2}\right)\right]}{2\left[n+2\left(1-\chi^{2}\right)\right]}\right\} .
$$

Assuming an interior solution, the first order condition yields

$$
t(\mathbf{1} / \mathbf{2}, \mathbf{1}, \chi, n)=\frac{n(1+2 \chi)^{2}-1}{1-2 \chi^{2}+2 n[1+2 \chi(1+\chi)]} .
$$

Given (34), we obtain

$$
q_{i}(1 / 2 ; t(\mathbf{1} / \mathbf{2}, \mathbf{1}), \mathbf{1} / \mathbf{2}, \chi, n)=1 /\left\{1-2 \chi^{2}+2 n[1+2 \chi(1+\chi)]\right\}
$$

and $\pi_{i}(1 / 2,1 ; t(\mathbf{1} / \mathbf{2}, \mathbf{1}), \mathbf{1} / \mathbf{2}, \chi, n, f)=\left(3-2 \chi^{2}\right) / 2\left\{1-2 \chi^{2}+2 n[1+2 \chi(1+\chi)]\right\}^{2}-f$.

On the other hand, if innovation is not optimal, $\theta_{i}=1$ and $\sigma_{i}=0, \forall i=1, \ldots, n$. The government's objective function becomes

$$
x^{o}+\frac{2 n(1-t)}{2 n+4-3 \chi^{2}}\left\{t+\frac{(1-t)\left[n-\left[n(2+3 \chi)^{2}-6\left(2-\chi^{2}\right)\right] / 4\right]}{2 n+4-3 \chi^{2}}\right\} .
$$


Assuming an interior solution, the first order condition yields

$$
t(\mathbf{1}, \mathbf{0}, \chi, n)=\frac{n(2+3 \chi)^{2}-4}{4-6 \chi^{2}+n[8+3 \chi(4+3 \chi)]}
$$

Given (35), we obtain

$$
\begin{gathered}
q_{i}(1 ; t(\mathbf{1}, \mathbf{0}), \mathbf{1}, \chi, n)=4 /\left\{4-6 \chi^{2}+n[8+3 \chi(4+3 \chi)]\right\} \\
\text { and } \pi_{i}(1,0 ; t(\mathbf{1}, \mathbf{0}), \mathbf{1}, \chi, n)=12\left(2-\chi^{2}\right) /\left\{4-6 \chi^{2}+n[8+3 \chi(4+3 \chi)]\right\}^{2} \text {. }
\end{gathered}
$$

The social welfare levels are

$$
\left\{\begin{array}{c}
u(t(\mathbf{1} / \mathbf{2}, \mathbf{1}), \chi, n, f)=x^{o}+\frac{n}{2\left\{1-2 \chi^{2}+2 n[1+2 \chi(1+\chi)]\right\}}-n f \\
u(t(\mathbf{1}, \mathbf{0}), \chi, n)=x^{o}+\frac{2 n}{4-6 \chi^{2}+n[8+3 \chi(4+3 \chi)]}
\end{array} .\right.
$$

\section{Emission Tax}

In this section, we assume that the government uses an emission tax $\tau$ to control the pollutant emissions. The timing of the game is the same as in the previous section. The sole difference between the two sections is the type of tax. We assume that firm $i$ 's profit function is as follows:

$$
\pi_{i}=p(Q) q_{i}-\frac{q_{i}^{2}}{2}-\theta_{i} \gamma_{i}\left(a_{i}-r_{i}\right)^{2}-\chi a_{i} q_{i}-\frac{r_{i}^{2}}{2}-\sigma_{i} f-\tau e_{i},
$$

The tax revenue is returned to the consumer in a lump-sum fashion. The welfare level in the economy is

$$
u=x^{o}+\sum_{i=1}^{n} \pi_{i}+\tau \sum_{i=1}^{n} e_{i}+\left[(1-p)^{2}-E^{2}\right] / 2
$$

If the government levies a tax on emissions, the firms have incentives to produce abatement and exert effort in green R\&D. Hence, the analysis below is carried out for $\chi \in[-1 / 2,1 / 2]$ rather 
than distinguishing the cases with and without economies of scope. Assume that $a_{i}>0, q_{i}>0$ and $r_{i}>0$. Firm $i$ 's first order conditions yield

$$
\begin{aligned}
& 2 \theta_{i}\left(a_{i}-r_{i}\right)=\tau-\chi q_{i}, \\
& 2 q_{i}=p-\chi a_{i}-\tau, \\
& 2 \theta_{i}\left(a_{i}-r_{i}\right)=r_{i} .
\end{aligned}
$$

Solving the system of equations (39) - (41) yields

$$
\begin{aligned}
& a_{i}=-\frac{p\left(1+2 \theta_{i}\right) \chi-\tau(2+\chi)\left(1+2 \theta_{i}\right)}{4 \theta_{i}-\left(1+2 \theta_{i}\right) \chi^{2}}, \\
& q_{i}=\frac{2 \theta_{i} p-\tau\left[2 \theta_{i}+\left(1+2 \theta_{i}\right) \chi\right]}{4 \theta_{i}-\left(1+2 \theta_{i}\right) \chi^{2}}, \\
& r_{i}=-\frac{2 \theta_{i}[p \chi-\tau(2+\chi)]}{4 \theta_{i}-\left(1+2 \theta_{i}\right) \chi^{2}} .
\end{aligned}
$$

Let $\beta_{j} \equiv\left[2 \theta_{j}+\left(1+2 \theta_{j}\right) \chi\right] /\left[4 \theta_{j}-\left(1+2 \theta_{j}\right) \chi^{2}\right]$. Since $Q=\sum_{j=1}^{n} q_{j}$ and $p=1-Q$, we have

$$
\begin{gathered}
p=\frac{1+\tau \sum_{j=1}^{n} \beta_{j}}{1+2 \sum_{j=1}^{n} \alpha_{j}}, \\
Q=\frac{2 \sum_{j=1}^{n} \alpha_{j}-\tau \sum_{j=1}^{n} \beta_{j}}{1+2 \sum_{j=1}^{n} \alpha_{j}} .
\end{gathered}
$$

Combining (43) with (45), we can write 


$$
q_{i}\left(\theta_{i} ; \tau, \boldsymbol{\theta}_{-i}\right)=\frac{2 \alpha_{i}\left(\theta_{i}\right)\left[1+\tau\left(\beta_{i}\left(\theta_{i}\right)+\sum_{h \neq i}^{n} \beta_{h}\left(\theta_{h}\right)\right]\right.}{1+2 \alpha_{i}\left(\theta_{i}\right)+2 \sum_{h \neq i}^{n} \alpha_{h}\left(\theta_{h}\right)}-\tau \beta_{i}\left(\theta_{i}\right) .
$$

The following result demonstrates that each firm produces more output when it innovates.

Proposition 7. $q_{i}\left(1 / 2 ; \tau, \boldsymbol{\theta}_{-i}\right)>q_{i}\left(1 ; \tau, \boldsymbol{\theta}_{-i}\right)$.

Proof. Note that (47) is $q_{i}\left(\theta_{i} ; \tau, \boldsymbol{\theta}_{-i}\right)=\frac{2 \alpha_{i}\left(\theta_{i}\right)\left[1+\tau \sum_{h \neq i}^{n} \beta_{h}\left(\theta_{h}\right)\right]}{1+2 \alpha_{i}\left(\theta_{i}\right)+2 \sum_{h \neq i}^{n} \alpha_{h}\left(\theta_{h}\right)}-\frac{\tau \beta_{i}\left(\theta_{i}\right)\left(1+2 \sum_{h \neq i}^{n} \alpha_{h}\left(\theta_{h}\right)\right)}{1+2 \alpha_{i}\left(\theta_{i}\right)+2 \sum_{h \neq i}^{n} \alpha_{h}\left(\theta_{h}\right)}$. We also know that $\frac{2 \alpha_{i}(1 / 2)\left[1+\tau \sum_{h \neq i}^{n} \beta_{h}\left(\theta_{h}\right)\right]}{1+2 \alpha_{i}(1 / 2)+2 \sum_{h \neq i}^{n} \alpha_{h}\left(\theta_{h}\right)}>\frac{2 \alpha_{i}(1)\left[1+\tau \sum_{h \neq i}^{n} \beta_{h}\left(\theta_{h}\right)\right]}{1+2 \alpha_{i}(1)+2 \sum_{h \neq i}^{n} \alpha_{h}\left(\theta_{h}\right)}$. It follows that $q_{i}\left(1 / 2 ; \tau, \boldsymbol{\theta}_{-i}\right)>q_{i}\left(1 ; \tau, \boldsymbol{\theta}_{-i}\right)$ if and only if

$$
\frac{\tau \beta_{i}(1)\left(1+2 \sum_{h \neq i}^{n} \alpha_{h}\left(\theta_{h}\right)\right)}{1+2 \alpha_{i}(1)+2 \sum_{h \neq i}^{n} \alpha_{h}\left(\theta_{h}\right)}>\frac{\tau \beta_{i}(1 / 2)\left(1+2 \sum_{h \neq i}^{n} \alpha_{h}\left(\theta_{h}\right)\right)}{1+2 \alpha_{i}(1 / 2)+2 \sum_{h \neq i}^{n} \alpha_{h}\left(\theta_{h}\right)} .
$$

Note that

$$
\frac{2+3 \chi}{4-3 \chi^{2}+2+2\left(4-3 \chi^{2}\right) \sum_{h \neq i}^{n} \alpha_{h}\left(\theta_{h}\right)}>\frac{1+2 \chi}{4\left(1-\chi^{2}\right)+2+8\left(1-\chi^{2}\right) \sum_{h \neq i}^{n} \alpha_{h}\left(\theta_{h}\right)} .
$$

When $\chi \in(-1 / 2,1 / 2]$, (48) holds if and only if

$$
(2+3 \chi)\left[4\left(1-\chi^{2}\right)+2+8\left(1-\chi^{2}\right) \sum_{h \neq i}^{n} \alpha_{h}\left(\theta_{h}\right)\right]>(1+2 \chi)\left[4-3 \chi^{2}+2+2\left(4-3 \chi^{2}\right) \sum_{h \neq i}^{n} \alpha_{h}\left(\theta_{h}\right)\right] .
$$

It is true because $2(1+\chi)+\left(4+4 \chi-5 \chi^{2}-6 \chi^{3}\right)\left(1+\sum_{h \neq i}^{n} \alpha_{h}\left(\theta_{h}\right)\right)>0$. See figure 1 . 


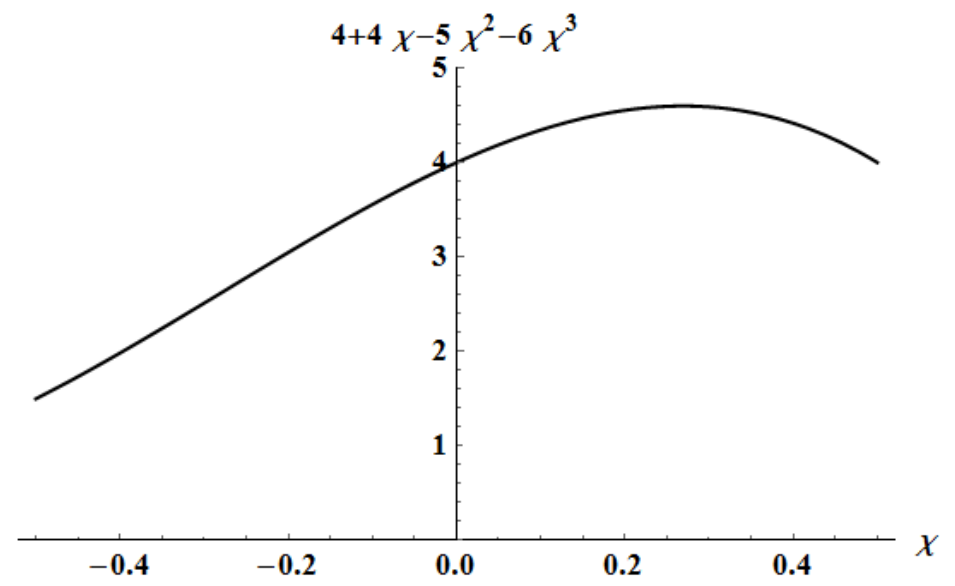

Figure 1. $\left(4+4 \chi-5 \chi^{2}-6 \chi^{3}\right)>0$

Q.E.D.

Firm $i$ 's profit in the third stage is

$$
\pi_{i}\left(\theta_{i}, \sigma_{i}, \chi, f ; \tau, \boldsymbol{\theta}_{-i}\right)=\left[3-\frac{\left(1+2 \theta_{i}\right) \chi^{2}}{2 \theta_{i}}\right] \frac{q_{i}^{2}\left(\theta_{i} ; \tau, \boldsymbol{\theta}_{-i}\right)}{2}+\frac{\tau^{2}\left(1+2 \theta_{i}\right)}{4 \theta_{i}}-\sigma_{i} f .
$$

Consider the second stage. Given (49), we obtain:

Proposition 8. $\theta_{i}=1 / 2$ and $\sigma_{i}=1$ if and only if

$$
f \leq \frac{2\left(3-2 \chi^{2}\right) q^{2}\left(1 / 2 ; \tau, \boldsymbol{\theta}_{-i}\right)-3\left(2-\chi^{2}\right) q^{2}\left(1 ; \tau, \boldsymbol{\theta}_{-i}\right)-\tau^{2}}{4}
$$

Proof. From (49), $\pi_{i}\left(1 / 2,1, \chi, f ; \tau, \boldsymbol{\theta}_{-i}\right) \geq \pi_{i}\left(1,0, \chi ; \tau, \boldsymbol{\theta}_{-i}\right)$ if and only if (50) holds. Q.E.D.

For future reference, let us denote $f=f^{3}$ where (50) holds with equality. Anticipating the firms' choices in the second and third stages, the government chooses $\tau \in[0,1]$ to maximize (37) subject to (42) - (46) and $E=Q-A$. If it is optimal to innovate, $\theta_{i}=1 / 2$ and $\sigma_{i}=1, \forall i=1, \ldots, n$. The government's objective function reduces to 


$$
\begin{aligned}
& x^{o}+n\left(\tau^{2}-f\right)+\frac{n}{2\left(1-\chi^{2}\right)} \times \\
& \left\{\frac{\left(n+3-2 \chi^{2}\right)[\psi-\tau(1+2 \chi)]^{2}}{4\left(1-\chi^{2}\right)}+[(1+2 \chi) \psi-\tau(5+4 \chi)]\left[\tau-\frac{n[(1+2 \chi) \psi-\tau(5+4 \chi)]}{4\left(1-\chi^{2}\right)}\right]\right\}
\end{aligned}
$$

where $\psi \equiv\left[n \tau(1+2 \chi)+2\left(1-\chi^{2}\right)\right] /\left[n+2\left(1-\chi^{2}\right)\right]$. Assuming an interior solution, the first order condition yields

$$
\tau(\mathbf{1} / \mathbf{2}, \mathbf{1}, \chi, n)=\frac{(1+2 \chi)[n(5+2 n+4 \chi)-1]}{9+2 \chi(2+\chi)(1-4 \chi)+2 n\left[2 n^{2}+(11+8 \chi) n+17+\chi(22+6 \chi)\right]} .
$$

Given the result, we obtain

$$
\begin{gathered}
q_{i}(1 / 2 ; \tau(\mathbf{1} / \mathbf{2}, \mathbf{1}), \mathbf{1} / \mathbf{2}, \chi, n)=\frac{(1+2 \chi)(5+2 n+4 \chi)}{9+2 \chi(2+\chi)(1-4 \chi)+2 n\left[2 n^{2}+(11+8 \chi) n+17+\chi(22+6 \chi)\right]} \\
\text { and } \pi_{i}(1 / 2,1 ; \tau(\mathbf{1} / \mathbf{2}, \mathbf{1}), \mathbf{1} / \mathbf{2}, \chi, n, f)=\frac{2 \tau^{2}(\mathbf{1} / \mathbf{2}, \mathbf{1})+\left(3-2 \chi^{2}\right) q_{i}^{2}(1 / 2 ; \tau(\mathbf{1} / \mathbf{2}, \mathbf{1}), \mathbf{1} / \mathbf{2})}{2}-f .
\end{gathered}
$$

If it is not optimal to innovate, $\theta_{i}=1$ and $\sigma_{i}=0, \forall i=1, \ldots, n$. The government's objective function becomes

$$
\begin{aligned}
& x^{o}+\frac{3 n \tau^{2}}{4}+\frac{n}{\left(4-3 \chi^{2}\right)} \times \\
& \left\{\frac{\left(2 n+3\left(2-\chi^{2}\right)\right)[[2 \phi-\tau(2+3 \chi)]]^{2}}{4\left(4-3 \chi^{2}\right)}+[(2+3 \chi) \phi-2 \tau(4+3 \chi)]\left[\tau-\frac{n[(2+3 \chi) \phi-2 \tau(4+3 \chi)]}{2\left(4-3 \chi^{2}\right)}\right]\right\}
\end{aligned}
$$

where $\phi \equiv\left[n \tau(2+3 \chi)+4-3 \chi^{2}\right] /\left[4+2 n-3 \chi^{2}\right]$. Assuming an interior solution, the first order condition yields

$$
\tau(\mathbf{1}, \mathbf{0}, \chi, n)=\frac{(2+3 \chi)[n(8+2 n+6 \chi)-2]}{28+3 \chi[4-\chi(11+6 \chi)]+n[9 n(n+2(3+2 \chi))+92+27 \chi(4+\chi)]} .
$$

Given (52), we obtain 


$$
\begin{gathered}
q_{i}(1 ; \tau(\mathbf{1}, \mathbf{0}), \mathbf{1}, \chi, n)=\frac{(2+3 n)(8+2 n+6 \chi)}{28+3 \chi[4-\chi(11+6 \chi)]+n[9 n(n+2(3+2 \chi))+92+27 \chi(4+\chi)]} \\
\quad \text { and } \pi_{i}(1,0 ; \tau(\mathbf{1}, \mathbf{0}), \mathbf{1}, \chi, n)=\frac{3\left[\tau^{2}(\mathbf{1}, \mathbf{0})+\left(2-\chi^{2}\right) q_{i}^{2}(1 ; \tau(\mathbf{1}, \mathbf{0}), \mathbf{1})\right]}{4} .
\end{gathered}
$$

The social welfare levels are

$$
\left\{\begin{array}{rl}
u(\tau(\mathbf{1} / \mathbf{2}, \mathbf{1}), \chi, n, f) \\
= & x^{o}+\frac{n(1+2 n)(7+2 n+4 \chi)}{9+2 \chi(2+\chi)(1-4 \chi)+2 n\left[2 n^{2}+(11+8 \chi) n+17+\chi(22+6 \chi)\right]}-n f \\
& u(\tau(\mathbf{1}, \mathbf{0}), \chi, n) \\
= & x^{o}+\frac{n(2+3 n)(11+3 n+6 \chi)}{28+3 \chi[4-\chi(11+6 \chi)]+n[9 n(n+2(3+2 \chi))+92+27 \chi(4+\chi)]}
\end{array} .\right.
$$

\section{Discussion}

Starting the analysis by considering the regime in which the government does not tax output or emissions, we show that firms do not have incentives to innovate in the absence of economies of scope. However, firms will find attractive to innovate in the presence of economies of scope if the fixed cost of adoption is sufficiently small. To examine the effectiveness of taxation in promoting innovation in the abatement technology, we need to "control" for the innovation incentives produced by economies of scope. Hence, the discussion focuses on the ranges of fixed-cost and complementarity parameters where firms do not find it attractive to innovate without a tax incentive.

In this discussion, we assume, for simplicity, that $n=2$ and $x^{\circ}=0$. The area under the $f^{1}$ curve in Figure 2, denoted $I$, represents the range where innovation occurs without taxation. The area above this curve in the quadrant with economies of scope represents the range in which innovation may occur due to a tax incentive. The area above the $f^{1}$ curve and below the $f^{3}$ curve 
in the quadrant with economies of scope, denoted II, is the range where firms find it attractive to innovate under the tax on emissions. The area between the $f^{1}$ and $f^{2}$ curves, denoted III, is the range where firms find it attractive to innovate under the energy tax. In the quadrant with diseconomies of scope, the area under the $f^{3}$ curve, denoted $I V$, is the range where firms innovate under the tax on emissions. Finally, the area above the $f^{2}$ and $f^{3}$ curves in the two quadrants, denoted $V$, is the range where innovation does not occur in the presence of either type of tax.

If we assume that any point in the two quadrants are equally likely to occur, and we focus our attention on the range where taxation may promote innovation incentives (i.e., the area that excludes area $I$ ), we find that the most likely scenario is the one where innovation does not occur. The chief cause is the fixed cost of adoption. The second most likely scenario is innovation under the energy tax. However, if we focus on the quadrant with diseconomies of scope only, the second most likely scenario is innovation under the tax on emissions. As we mentioned above, there is no chance that firms adopt the advanced abatement technology under the energy tax.

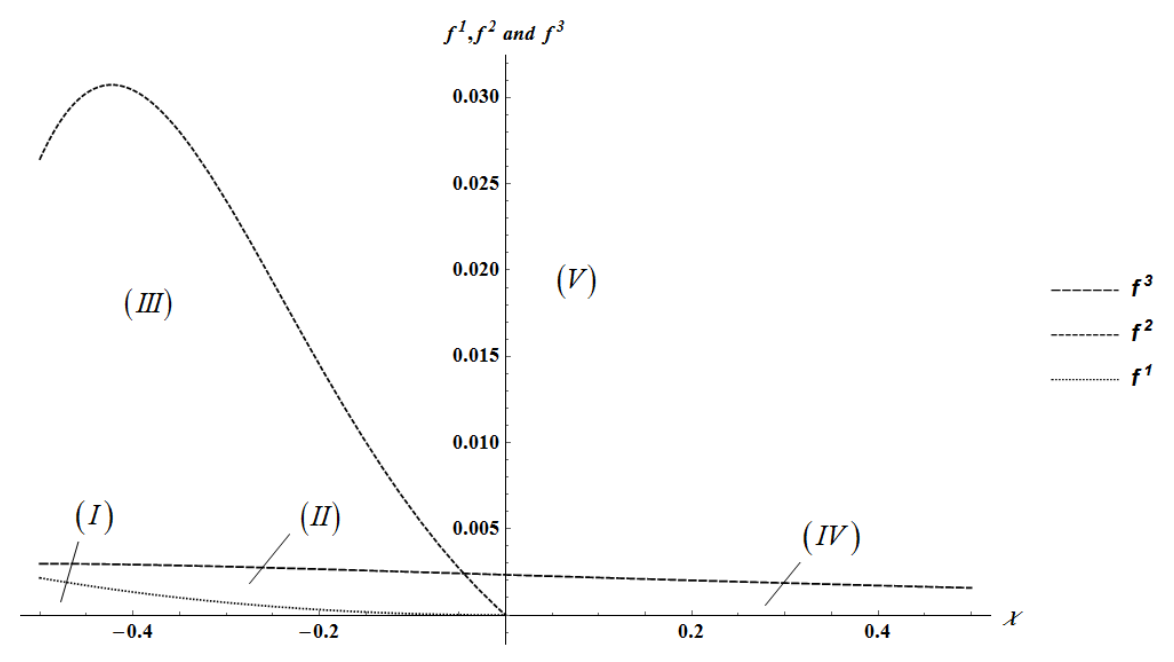

Figure 2. Isoprofit curves $f^{1}(\chi), f^{2}(\chi)$ and $f^{3}(\chi)$

Perhaps, the most intriguing message that we learn from examining Figure 2 is the fact that energy taxation may be more effective in promoting innovation than emission taxation in the 
presence of economies of scope. To understand why this happens, we focus our attention to the quadrant with economies of scope and assume that the fixed cost levels lie on the isoprofit curve $f=f^{1}$ in what follows. Under such circumstances, taxation promotes innovation incentives. Figure 3 depicts the optimal energy-tax and emission-tax curves when firms find it optimal to innovate. If the complementarity parameter is small in absolute value, both taxes are positive, but the two curves cross. The energy tax is initially higher than the emission tax, but eventually it becomes lower in the range where both taxes are non-negative. Since profits fall with taxes, they are initially higher under the emission tax, but then become higher under the energy tax as the complementarity parameter becomes larger in absolute value. The discrepancy becomes larger for higher absolute values of the complementarity parameter since the energy tax becomes negative, essentially becoming a subsidy. This pattern is essentially the reason why firms are more likely to innovate under the emission tax for low absolute values of the complementarity parameter, but then more likely to innovate under the energy tax under higher absolute values of the complementarity parameter.

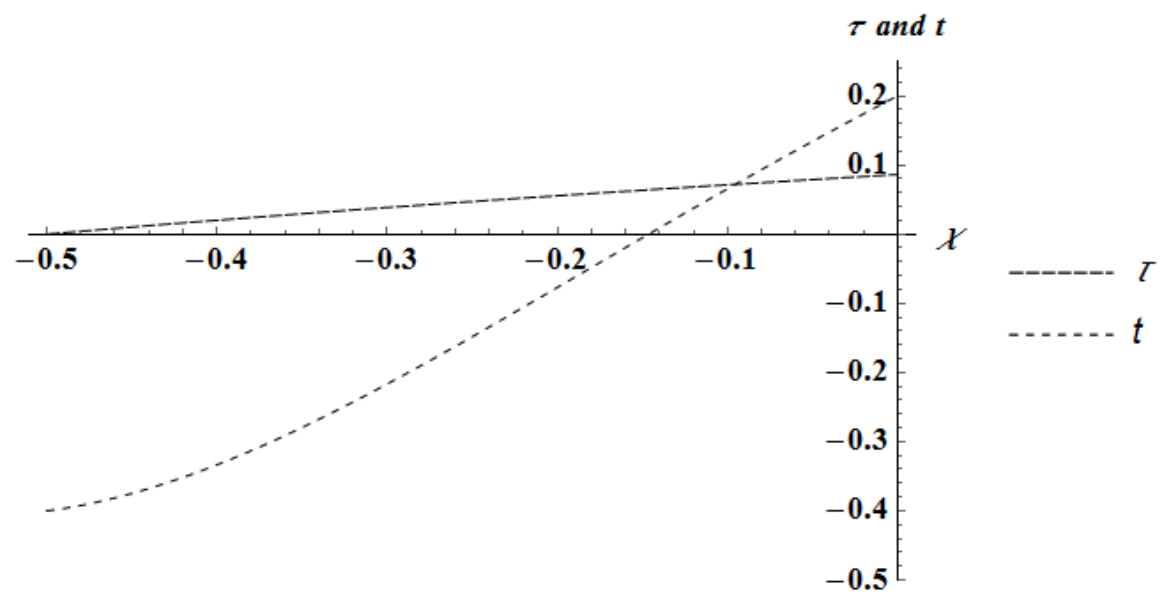

Figure 3. $\tau(\chi)$ and $t(\chi) ; n=2$ and $f=f^{1}$ 


\section{Conclusion}

This study builds on Cremer and Gahvari (2002) and examines circumstances under which environmental tax policy motivate oligopolistic firms to innovate in abatement technology. We find that if the multiproduct technology features diseconomies of scope the firms may find it optimal to innovate only if the tax utilized by the government is a tax on emissions. In such a case, innovation is optimal if the fixed cost of adoption is sufficiently small. An output tax does not provide incentives to innovate. If the multiproduct technology features economies of scope, innovation may be optimal even in the absence of an environmental tax. Considering the cases where innovation is not optimal in the absence of environmental taxation, we find that the energy tax outperforms the emission tax. In sum, we conclude that the most effective form of taxation to induce firms to innovate depends on the shape of the multiproduct technology, whether economies of scope are present or not.

\section{Acknowledgments}

I am very thankful for the helpful and insightful comments made by Yasunori Ouchida. Our paper has greatly benefited from comments and suggestions made by anonymous referees. This work is supported by JSPS KAKENHI Grant No. 25780166. Financial support from the Japan Society for the Promotion of Science is greatly appreciated. 


\section{References}

Acemoglu, D., P. Aghion, L. Bursztyn and D. Hemous (2012) "The Environment and Directed Technical Change”, American Economic Review, Vol.102 (1), pp. 131-166.

Bovenberg, A. L. and L. H. Goulder (2002) “Environmental Taxation and Regulation”, In: Alan J. Auerbach and Martin Feldstein Handbook of Public Economics, Vol. 23, pp. 1471-1545.

Cremer, H. and F. Gahvari (2001) “Second-best Taxation of Emissions and Polluting Goods”, Journal of Public Economics, Vol. 80, pp. 169-197.

Cremer, H. and F. Gahvari (2002) "Imperfect Observability of Emissions and Second-best Emission and Output Taxes”, Journal of Public Economics, Vol. 85, pp. 385-407.

Downing, P.B. and L. J. White (1986) “Innovation in Pollution Control”, Journal of Environmental Economics and Management, Vol. 13, pp. 18-29.

Fowlie, M. (2010) “Emissions Trading, Electricity Restructuring, and Investment in Pollution Abatement”, American Economic Review Vol.100, pp837-869.

Jaffe, A. B., R. G. Newell and R. N. Stavins (2002) “Environmental Policy and Technological Change”, Environmental and Resource Economics, Vol. 22, pp. 41-69.

Jung, C., K. Krutilla and R. Boyd (1996) "Incentives for Advanced Pollution Abatement Technology at the Industry Level: An Evaluation of Policy Alternatives”, Journal of Environmental Economics and Management, Vol. 30, pp. 95-111.

Katsoulacos, Y. and A. Xepapadeas (1996) "Emission Taxes and Market Structure", in Environmental Policy and Market Structure, edited by Carraro, C., Y. Katsoulacos and A. Xepapadeas, pp. 3-22, Netherlands: Kluwer Academic Publishers. 
Milliman, S. R. and R. Prince (1989) "Firm Incentives to Promote Technological Change in Pollution Control”, Journal of Environmental Economics and Management, Vol. 17, pp. 247265.

Organisation for Economic Co-operation and Development (2005), Glossary of Statistical Terms: Environmental Taxes. (https://stats.oecd.org/glossary/detail.asp?ID=6437).

Organisation for Economic Co-operation and Development (2010), Taxation, Innovation and the Environment, OECD, Paris.

Requate, T. and W. Unold (2003) "Environmental Policy Incentives to Adopt Advanced Abatement Technology: Will the True Ranking Please Stand Up?”, European Economic Review, Vol. 47, pp. 125-146.

Schmutzler, A. and L. H. Goulder (1997) “The Choice between Emission Taxes and Output Taxes under Imperfect Monitoring”, Journal of Environmental Economics and Management, Vol. 32, pp. 51-64. 